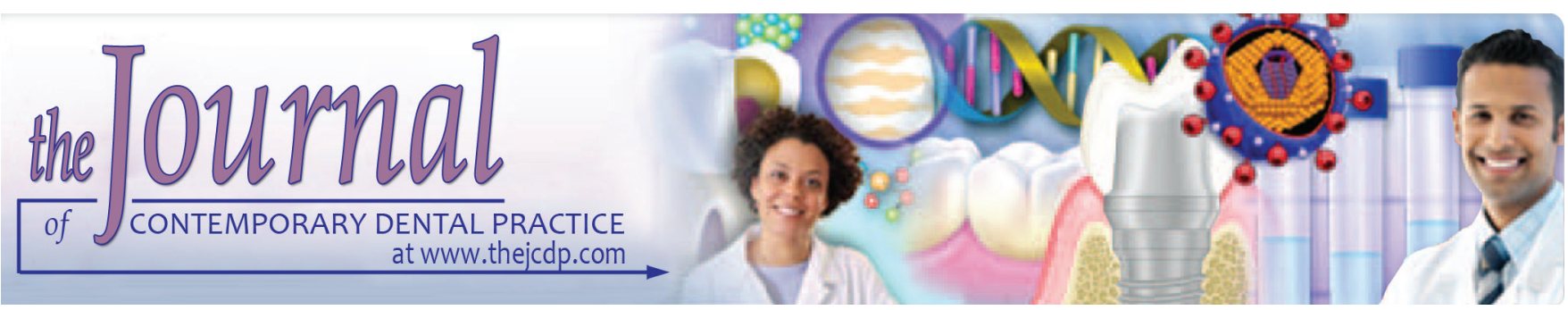

\title{
Effect of using the New Glass Fiber Pin in Resin Composite Restorations
}

\author{
${ }^{1}$ Clóvis L de Moraes Melo Neto, ${ }^{2}$ Guilherme T Costa, ${ }^{3}$ Tarso Lorga, ${ }^{4}$ Gabriela C Santin \\ ${ }^{5}$ José Mondelli, ${ }^{6}$ Sérgio Sábio
}

\section{ABSTRACT}

Aim: The purpose was to compare the fracture strength between restorations containing the metal pin (MP) and those containing the glass fiber pin (GFP).

Materials and methods: Forty-five healthy bovine anterior teeth were used in this study. A preparation of $4 \mathrm{~mm} \times 4 \mathrm{~mm}$ was created on the incisal surface of each tooth. All teeth were prepared in the same way. The teeth were randomly divided into three groups $(n=15)$ : group I-control: teeth restored with resin composite (RC) only, without reinforcement; group II-Each tooth was restored with a MP and RC; group III-Each tooth was restored with a GFP and RC. The specimens were left in an oven at a temperature of $37^{\circ} \mathrm{C}$ for 24 hours before performing the fracture strength tests. The fracture strength test was performed in a universal test machine at an angle of $90^{\circ}$.

Results: The Tukey test ( $p \leq 0.05)$ showed that for the variable maximum force (kgf), there was no statistically significant difference among the groups $(p=0.272)$. The chi-square test showed that groups II and III presented over $70 \%$ of cohesiveadhesive type fractures when compared with group I (over $70 \%$ of adhesive fractures), and this difference was statistically significant $(p<0.05)$.

Conclusion: The pins tested did not increase the fracture resistance of the restorations (RC) in comparison with group I (without reinforcement); however, with the use of the MP and GFP, there was a predominance of cohesive-adhesive fractures (groups II and III).

Clinical significance: Evaluate if the new GFP can generate greater resistance to fracture of $\mathrm{RC}$ restorations.

Keywords: Glass fiber pins, Laboratory research, Metal pin.

${ }^{1-4,6}$ Department of Dentistry, State University of Maringá Maringá, Paraná, Brazil

${ }^{5}$ Department of Operative Dentistry, Endodontics and Dental Materials, University of São Paulo, São Paulo, Brazil

Corresponding Author: Clóvis Lamartine de Moraes Melo Neto Department of Dentistry, State University of Maringá, Maringá Paraná, Brazil, Phone: +5544997579986, e-mail: lamartineclovis@ gmail.com
How to cite this article: de Moraes Melo Neto CL, Costa GT, Lorga T, Santin GC, Mondelli J, Sábio S. Effect of using the New Glass Fiber Pin in Resin Composite Restorations. J Contemp Dent Pract 2018;19(5):541-545.

Source of support: Nil

Conflict of interest: None

\section{INTRODUCTION}

The MP is used in circumstances of extensive tooth structure losses associated with a direct amalgam ${ }^{1}$ or RC restorations. The purpose of these MPs is to provide restorations with more retention or greater fracture strength, by avoiding possible endodontic treatments, which weaken the teeth ${ }^{2}$ and indirect restorations. However, there are controversies in the literature about this proposal., ${ }^{3,4}$ Over the course of years, adhesive techniques have been increasingly improved and many dentists stopped using these MPs. ${ }^{5,6}$ There are three types of MPs: stainless steel (nickel-chrome); titanium alloy (titanium, vanadium, and aluminum), and pure titanium. However, those most used are made of titanium alloy or pure titanium, because of trying to reduce the use of nickel-chrome, ${ }^{6}$ due to allergic reactions.

The technique for inserting MPs may be complex in situations in which there is a small quantity of tooth structure, which forces the operator to prepare a small orifice with little thickness and depth. ${ }^{3}$ The shape of the bur for preparing the orifice and the ease of access are responsible for the successful insertion of $\mathrm{MP}^{7}$ Therefore, should an error occur during the preparation of this orifice, it could become excessively widened, harming or making it unfeasible for the MP to be retained or inserted.

The MPs may harm the esthetic appearance when they are associated with RC restorations, particularly in anterior teeth, in addition to the absence of a chemical bond between the MPs and resin materials. Moreover, the act of threading the MP into dentin promotes stress ${ }^{5}$ 
which may generate tooth ${ }^{4-6}$ and/or restoration fractures, dental fissures, pulp hypersensitivity, ${ }^{8}$ perforation of the pulp, or periodontium. ${ }^{5}$ Considering these esthetic disadvantages and technical complications, other materials have been proposed as a way to replace the MPs to reinforce $\mathrm{RC}$ restorations, such as, for example, the GFP of the company ANGELUS.

This GFP is inserted by adhesive cementation, and thus, the stresses caused by threading that occurs with the MP is avoided. The white color of the GFP may make it easier to obtain esthetics in RC restorations, particularly in the region of the anterior teeth. Furthermore, the GFP may form a composite in association with the $\mathrm{RC}_{,}^{9-12}$ in addition to having mechanical properties similar to those of dentin. ${ }^{9,10,13,14}$ Glass fibers have been used for reinforcing the properties of resin materials. When present in sufficient quantities, they may improve the properties of flexural and compressive strength of RC., 9,10 Therefore, the aim of this study was to verify whether the GFP could improve the capacity of the $\mathrm{RC}$ restoration to resist fracture, when compared with the traditional method (reinforcement with MP), or to the method with the absence of any type of reinforcement. Another aim was to verify the type of fracture prevalent in each group.

\section{MATERIALS AND METHODS}

Forty-five bovine anterior teeth (central incisors) were collected for this research 1 hour after the animals were slaughtered. The teeth were cleaned and stored at ambient temperature, in distilled water that was changed every week. Fractured teeth, with extensive wear, absence of vestibular or lingual enamel, structural defects, and primary teeth, were excluded.

The teeth were sectioned with a hand-piece (KavoJoinville, Santa Catarina, Brazil) and double-faced diamond disk (KGSorensen, Zenith Dental Aps, Agerskov,

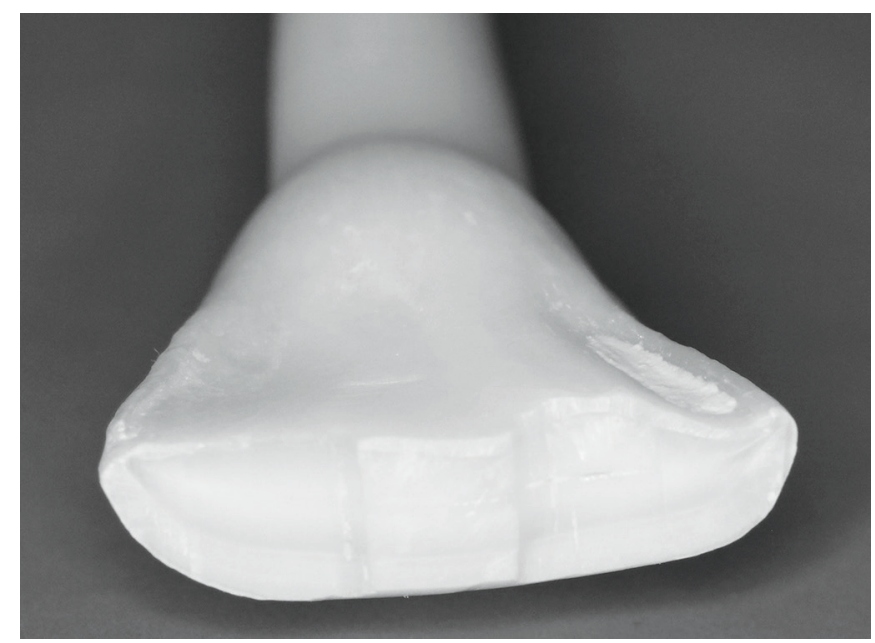

Fig. 1: Top view of incisal plateau
Denmark) under constant irrigation. The cut was made in the mesiodistal direction from 3 to $4 \mathrm{~mm}$ below the incisal edge so that there would be no pulp exposure that would weaken the dental structure, or make it unfeasible to insert the pin. Afterward, two more vertical cuts perpendicular to the incisal edge were made at a distance of $4 \mathrm{~mm}$ from one another, and $0.5 \mathrm{~mm}$ deep. Thus, a square preparation (incisal plateau) was formed measuring approximately $4 \mathrm{~mm}$ in the mesiodistal by $4 \mathrm{~mm}$ in the vestibular-lingual direction. The incisal part outside of this plateau was worn $0.5 \mathrm{~mm}$ (Fig. 1) and after preparation of the incisal plateau, manual finishing was performed with doublefaced disks (KG Sorensen).

The roots of the teeth were embedded in acrylic resin at the level of cemento-enamel junction. The teeth were randomly distributed into three groups: group I (control) $(\mathrm{n}=15)$ was restored with RC only, without reinforcement. Each incisal plateau was etched with 37\% phosphoric acid (Angelus Ind., Londrina, Paraná, Brazil) for 15 and 30 seconds for dentin and enamel respectively. The surfaces were washed with a jet of air and water for 40 seconds, and the excess humidity was removed with absorbent paper. The adhesive system Single Bond 2 (3M ESPE, St. Paul, Minnesota, USA) was applied on the enamel and dentin surfaces, in accordance with the manufacturer's recommendations. Then the adhesive was light polymerized for 10 seconds with a light-emitting diode light appliance. The RC Bulk Fill (3M ESPE, St. Paul, Minnesota, USA) was added with an insertion spatula, by the incremental technique, and each $2 \mathrm{~mm}$ increment was light activated for 20 seconds. Thus, a restoration was formed, measuring approximately $3.4 \mathrm{~mm}$ high, with $3 \mathrm{~mm}$ vestibular-lingual thickness above the step lingual, with $4 \mathrm{~mm}$ mesio-distal thickness and $0.5 \mathrm{~mm}$ high lingual step above the incisal plateau (Fig. 2).

In group II (MP) $(\mathrm{n}=15)$, a $1 / 4$ metal bur (SS White, Rio de Janeiro, Brazil), associated with low speed

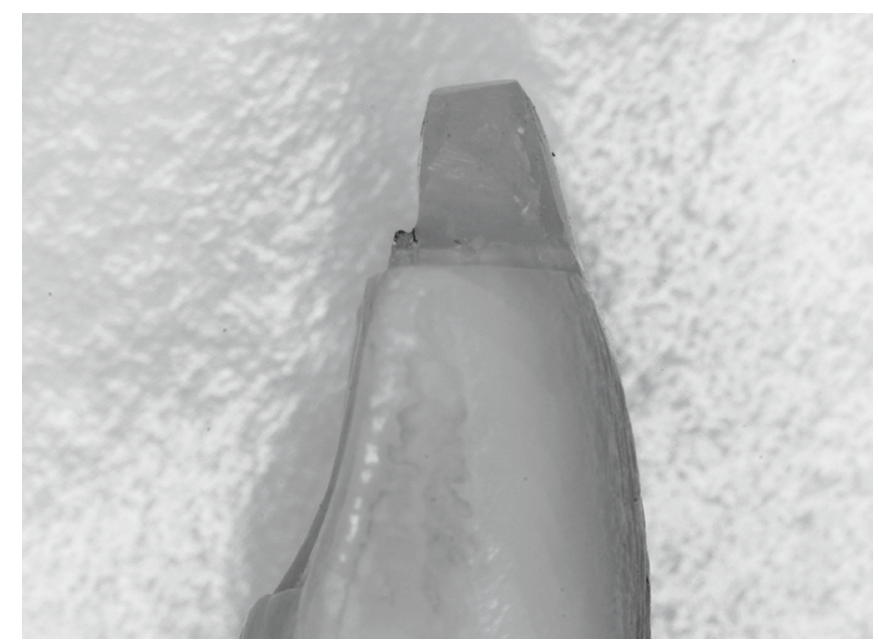

Fig. 2: Side view. Observe step in RC on lingual surface 
(Kavo-Joinville, Santa Catarina, Brazil), was used under irrigation, to prepare an orifice in the center of the incisal plateau in the dentin (at a distance of $1 \mathrm{~mm}$ from the dentin-enamel junction) for the purpose of guiding the preparation bur of the Edenta kit (Retopin Gold, Edenta, Switzerland). A gingival needle (Injex, Industrias Cirúrgicas LTDA, São Paulo, Brazil) was introduced into the orifice to ensure absence of communication with the pulp chamber after preparation with the bur of the kit. The approximately $4.5 \mathrm{~mm}$ long pin (Retopin Gold, Edenta ${ }^{\circledR}$ ) was manually inserted, threaded, until it ruptured, in accordance with the fixation instructions provided by the manufacturer. With rupture, approximately $2.25 \mathrm{~mm}$ of the pin became inserted into the plateau ${ }^{6}$ and $2.25 \mathrm{~mm}$ remained exposed, perpendicular to the plateau. The RC restorations were then performed in the same manner as that used in group I.

For group III $(n=15)$, the orifice was made using the preparation bur (Micropin, Angelus Ind., Londrina, Paraná, Brazil), in a similar manner to that done in group II. The GFP (Micropin, Angelus) was used in this group (Fig. 3). After conclusion of the orifice, silane (Angelus Indústria de Produtos Odontológicos Ltd., Londrina-PR) was applied with a microbrush (KG Sorensen), and a time of 60 seconds was waited for the product to volatilize. The plateau was etched (except inside the orifice), washed, dried, and the adhesive was applied in the same manner as was done in group I (except inside the orifice) and light polymerized for 10 seconds. A small quantity of self-etching dual resin cement (RelyX U200, 3M ESPE, Seefeld, Germany) was manipulated for 20 seconds until it was homogenized and then applied to the stem of the GFP, which was then introduced into the orifice and light activated for 40 seconds. As in group II, $2.25 \mathrm{~mm}$ of the pin remained externally exposed, and $2.25 \mathrm{~mm}^{6}$ remained internally fixed. After application and polymerization of the adhesive Single Bond 2 (3M ESPE) on the coronal part

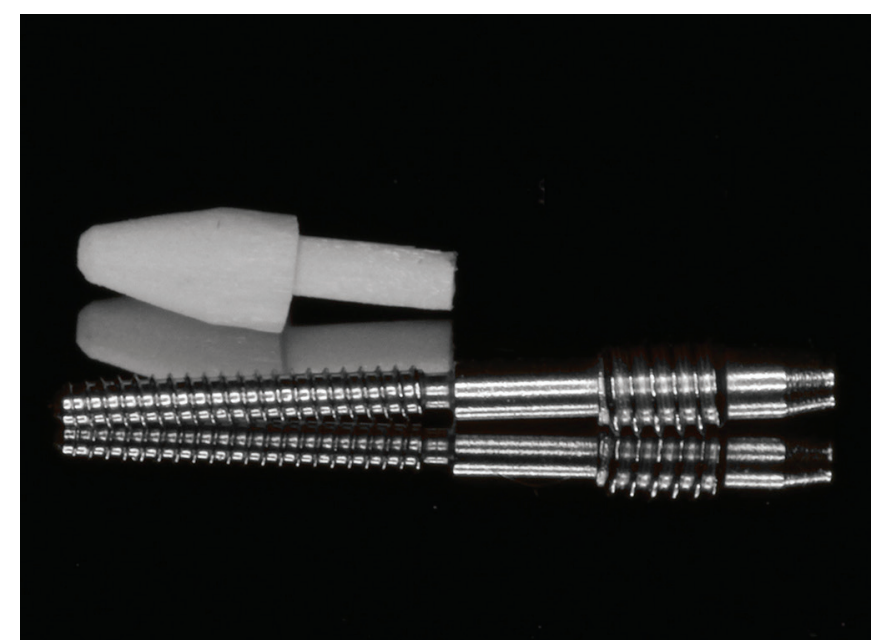

Fig. 3: Metal and glass fiber pin of the GFP inserted, the restoration was performed in the same way as was done in groups I and II.

The specimens of the three groups were stored for 1 week in distilled water for hygroscopic expansion of the RC. A propelling pencil was used to mark the angle between the gingival and axial wall of the RC on the lingual surface (Fig. 2). The specimens were left in an oven at a temperature of $37^{\circ} \mathrm{C}$ for 24 hours before performing the fracture strength tests in the universal test machine (EMIC DL 1.000, São José dos Pinhais, Brazil).

A compressive force was applied on the $\mathrm{RC}$ in the region delimited by the graphite at an angle of $90^{\circ}$ (lingual surface). The constant speed of force application was 1 mm per minute until fracture of the restoration occurred. Each test specimen was individually stored after the tests for evaluating the type of fracture, by means of a binocular loupe at $10 \times$ magnification. After obtaining the results, they were included in a database and analyzed by means of Statistical Package for Social Sciences 20.0 (SPSS-IBM Corp., Armonk, NY, 2012), and values of $\mathrm{p} \leq$ 0.05 were considered significant. The normality of data was verified by means of the Shapiro-Wilk test and the variable maximum force, measured in kgf, was analyzed by means of analysis of variance (ANOVA) and Tukey post-test. The type of fracture between the groups was analyzed by chi-square test.

\section{RESULTS}

The mean and standard deviation for group I were 11.26 \pm 2.38 [95\% confidence interval (CI)], for group II, 12.84 $\pm 4.24(95 \% \mathrm{CI})$ and for group III, $13.33 \pm 3.95$ (95\% CI). As regards the variable maximum force in $\mathrm{kgf}$, there was no statistically significant difference between groups I, II, and III ( $p=0.272)$, thus showing a similar fracture strength, irrespective of the type of pin, and (groups II and III) with group I (control) (Table 1). However, the groups with pins (groups II and III) presented higher prevalence of cohesive-adhesive type fractures (over $70 \%$ ) when compared with group I or control, and this difference was statistically significant $(\mathrm{p}<0.05)$ (Table 2$)$.

\section{DISCUSSION}

In this study, bovine teeth were used to prepare the test specimens. This method was in agreement with the standards used by other authors. ${ }^{4,15-19}$

Table 1: Fracture resistance (kgf)

\begin{tabular}{ll}
\hline & Fracture force 95\% Cl Mean ( \pm SD) \\
\hline Control (I) & $11.26( \pm 2.38)^{\mathrm{a}}$ \\
Metal (II) & $12.84( \pm 4.24)^{\mathrm{a}}$ \\
Glass fiber (III) & $13.33( \pm 3.95)^{\mathrm{a}}$ \\
\hline ANOVA and Tukey posttest. Equal letters represent similar means
\end{tabular}

$(p>0.05)$ 
Table 2: Fracture type (\%)

\begin{tabular}{|c|c|c|c|c|c|c|}
\hline Control (I) & & Metal (II) & & Glass fiber (III) & & $p$-value \\
\hline Adhesive & $11(73.3 \%)$ & Adhesive & $3(20.0 \%)$ & Adhesive & $4(26.7 \%)$ & 0.005 \\
\hline Cohesive-adhesive & $4(26.7 \%)$ & Cohesive-adhesive & $12(80.0 \%)$ & Cohesive-adhesive & $11(73.3 \%)$ & \\
\hline
\end{tabular}

Chi-square test

For re-establishing canine or incisal guides with RC during excursive mandibular movements, high fracture strength is required. This property is important, due to the lever arm that is formed in the dental region during these movements, which may generate fracture of both the restoration and tooth. With the use of the GFP in the $\mathrm{RC}$, the composite formed was expected to be able to generate a significant increase in fracture strength; however, the fracture strength results obtained in this study showed no statistically significant differences among the groups I (11.26 kgf), II (12.8473 kgf), and III (13.3313 kgf). Therefore, it seemed to show the importance of the adhesive strength of the RC.

In the fracture type evaluation, the authors observed that in groups II and III, over $70 \%$ of the fractures were cohesive-adhesive, and in group I, over 70\% were adhesive (Table 2). This difference in fracture type that occurred between these groups showed a change in the region of the fulcrum provided by addition of the pin (MP or GFP). Relative to group III, the efficacy of the reinforcement of fibers in the RC depended on the quantity, treatment, length, shape, orientation, localization, and adhesive properties of the fibers, in addition to the composition of the RC itself. ${ }^{9-12}$ Therefore, cohesive type fractures observed in group III may suggest the need to improve RC properties.

Fennis et $\mathrm{al}^{5}$ evaluated the fracture strength in molars restored with RC only (without reinforcement), restored(RC) with the addition of MPs and restored(RC) with the addition of GFPs. The results showed that the fracture strength values of restorations with MPs or GFPs were higher with statistical significance than the values of the group without reinforcement. However, between the groups with MP and GFP, there were no significant differences. This may suggest that the quantity and distribution of the GFPs are important factors for the formation of a composite. According to Fennis et $\mathrm{al}^{5}$ the GFPs also showed less damage to dentin after the fractures, due to the lower modulus of elasticity and absence of stress (due to having no threading) in comparison with the MPs. In the present study, after fracture of the restorations, it was possible to observe that the MP was removed together with the restoration, or partially, and irrespective of the case, this abrupt exit of the MP generated damage to the dentin. However, the GFP was ruptured at its base, therefore, avoiding damage to the dentin.

Corroborating the prerogative of not using a pin in RC restorations, Muhlbauer et $\mathrm{al}^{3}$ tested the fracture strength in restorations of human central incisors with and without the use of reinforcement (MP). The authors found that there was no statistically significant difference between the groups, and thus, the presence of an MP in RC restorations did not influence the results of the fracture strength tests. On the contrary, Roberts et $\mathrm{al}^{4}{ }^{4}$ using preparations similar to those of the study of Muhlbauer et $\mathrm{al}^{3}$ but in bovine incisors, observed that the use of the MP as reinforcement of the restoration increased its fracture strength by $36 \%$. Therefore, a contradiction is observed between the researchers found in the literature. Therefore, new researches must verify alternative that may improve the structure of $R C$ using some type of additional reinforcement.

\section{CONCLUSION}

The addition of the pin (MP or GFP) in RC restorations did not significantly increase the results of the force necessary to rupture the restoration. However, the authors observed predominance of cohesive-adhesive fractures (over $70 \%$ ) in groups II and III, in which reinforcements (MP and GFP) were used when compared with group I.

\section{CLINICAL SIGNIFICANCE}

Evaluate if the new GFP can generate greater resistance to fracture of $\mathrm{RC}$ restorations.

\section{ACKNOWLEDGMENT}

Authors would like to thank Clóvis Lamartine.

\section{REFERENCES}

1. Shavell HM. Updating the Amalgapin technique for complex amalgam restorations. Int J Periodont Restorat Dent 1986 Oct; 6(5):22-35.

2. Oskoee SS, Oskoee PA, Navimipour EJ, Shahi S. In vitro fracture resistance of endodontically-treated maxillary premolars. Oper Dent 2007 Sep-Oct;32(5):510-514.

3. Muhlbauer JA, Dunn WJ, Roberts HW, Murchison DF. The effect of resin composite pins on the retention of class IV restorations. Oper Dent 2002 May-Jun;27(3):284-288.

4. Roberts HW, Hermesch CB, Charlton DG. The use of resin composite pins to improve retention of Class IV resin composite restorations. Oper Dent 2000 Jul-Aug;25(4):270-273.

5. Fennis WM, Wolke JG, Machado C, Creugers NH, Kreulen CM. Shear resistance of fiber-reinforced composite and metal dentin pins. Am J Dent 2013 Feb;26(1):39-43.

6. Christensen GJ. Achieving optimum retention for restorations. JADA 2004;131:1143-1145.

7. Papa J, Wilson PR, Tyas MJ. Pins for direct restorations. J Dent 1993 Oct;21(5):259-264. 
8. Chan CC, Chan KC. The retentive strength of slots with different width and depth versus pins. J Prosthet Dent 1987 Nov;58(5):552-557.

9. Fonseca RB, dePaulaMS, FavarãoIN,KasuyaAV, deAlmeidaLN, Mendes GA, Carlo HL. Reinforcement of dental methacrylate with glass fiber after heated silane application. Biomed Res Int 2014 May;2014:364398.

10. Fonseca RB, Marques AS, Bernades $\mathrm{K}$ de O, Carlo HL, Naves LZ. Effect of glass fiber incorporation on flexural properties of experimental composites. Biomed Res Int 2014 Jul;2014:542678.

11. Garoushi S, Vallittu PK, Lassila LV. Short glass fiber reinforced restorative composite resin with semi-inter penetrating polymer network matrix. Dent Mater 2007 Nov;23(11):1356-1362.

12. Garoushi SK, Lassila LV, Vallittu PK. Short fiber reinforced composite: the effect of fiber length and volume fraction. J Contemp Dent Pract 2006 Nov;7(5):10-17.

13. daCruzFZG, GrandeCZ, Roderjan DA, ArraisCAG,Samra APB, Calixto AL. Effect of etch-and-rinse and self-etching adhesive systems on hardness uniformity of resin cements after glass fiber post cementation. Eur J Dent 2012 Jul;6(3):248-254.
14. Lamichhane A, Xu C, Zhang F. Dental fiber-post resin base material: a review. J Adv Prosthodont 2014 Feb;6(1):60-65.

15. Soares FZ, Follak A, da Rosa LS, Montagner AF, Lenzi TL, Rocha RO. Bovine tooth is a substitute for human tooth on bond strength studies: a systematic review and meta-analysis of in vitro studies. Dent Mater 2016 Nov;32(11):1385-1393.

16. Schilke R, Lisson JA, Bauss O, Geurtsen W. Comparison of the number and diameter of dentinal tubules in human and bovine dentine by scanning electron microscopic investigation. Arch Oral Biol 2000 May;45(5):355-361.

17. Miyazaki M, Rikuta A, Iwasaki K, Ando S, Onose H. Influence of environmental conditions on bond strength of a resinmodified glass ionomer. Am J Dent 1997 Dec;10(6):287-290.

18. Nakabayashi N, Ashizawa M, Nakamura M. Identification of a resin-dentin hybrid layer in vital human dentin created in vivo: durable bonding to vital dentin. Quintessence Int 1992 Feb;23(2):135-141.

19. Teruel Jde D, Alcolea A, Hernández A, Ruiz AJ. Comparison of chemical composition of enamel and dentine in human, bovine, porcine and ovine teeth. Arch Oral Biol 2015 May;60(5):768-775. 